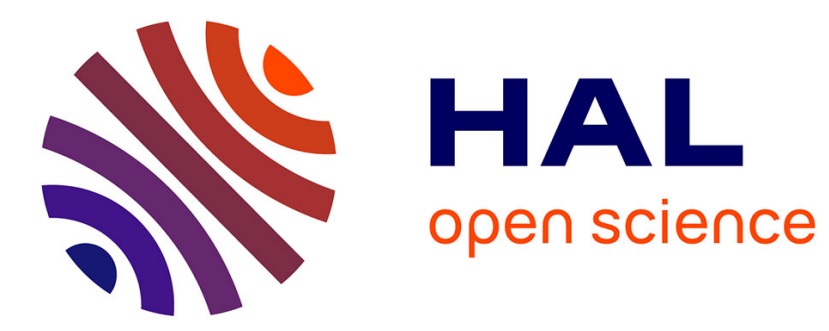

\title{
Ultrabright Fluorescent Polymeric Nanofibers and Coatings Based on Ionic Dye Insulation with Bulky Counterions
}

\author{
Anila Hoskere Ashoka, Andrey Klymchenko
}

\section{- To cite this version:}

Anila Hoskere Ashoka, Andrey Klymchenko. Ultrabright Fluorescent Polymeric Nanofibers and Coatings Based on Ionic Dye Insulation with Bulky Counterions. ACS Applied Materials \& Interfaces, 2021, 13 (24), pp.28889-28898. 10.1021/acsami.1c06436 . hal-03452589

HAL Id: hal-03452589

https://hal.science/hal-03452589

Submitted on 27 Nov 2021

HAL is a multi-disciplinary open access archive for the deposit and dissemination of scientific research documents, whether they are published or not. The documents may come from teaching and research institutions in France or abroad, or from public or private research centers.
L'archive ouverte pluridisciplinaire HAL, est destinée au dépôt et à la diffusion de documents scientifiques de niveau recherche, publiés ou non, émanant des établissements d'enseignement et de recherche français ou étrangers, des laboratoires publics ou privés. 


\section{Ultrabright Fluorescent Polymeric Nanofibers and}

\section{Coatings Based on Ionic Dye Insulation with Bulky}

\section{Counterions}

\section{Anila Hoskere Ashoka, ${ }^{a}$ Andrey S. Klymchenko ${ }^{a *}$}

Dr. Anila Hoskere Ashoka, Dr. S. Klymchenko

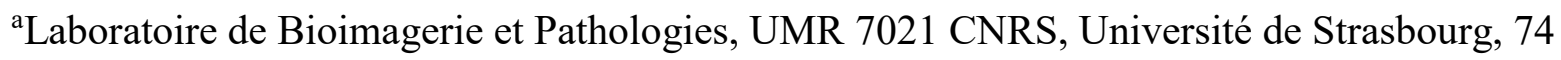
route du Rhin, 67401, Illkirch, France.

*Corresponding author e-mail: andrey.klymchenko@unistra.fr

KEYWORDS: fluorescent polymeric materials, bulky counterions, thin films, nanofibers, coatings.

ABSTRACT. Preparation of bright fluorescent materials based on polymers is hampered by a fundamental problem of aggregation-caused quenching (ACQ) of encapsulated dyes. Here, ultrabright fluorescent polymeric nanofibers and coatings are prepared based on a concept of ionic dye insulation with bulky hydrophobic counterions that overcomes the ACQ problem. It is found that bulky hydrophobic counterion perfluorinated tetraphenyl borate can boost $>100$-fold the fluorescence quantum yields of cationic dye octadecyl rhodamine B at high loading (30 wt $\%$ ) in a biocompatible poly(methyl methacrylate) (PMMA). The concept is applicable to both rhodamine 
and cyanine dyes, which results in bright fluorescent polymeric materials of four different colors spanning from blue to near-infrared. It allows preparation of electrospun polymeric fibers with nearly 100-fold higher dye loading (30 wt $\%$ ), while preserving good fluorescence quantum yields (31\%), which implies drastic improvement in fluorescence brightness. The counterion-based polymeric materials are also validated as coatings of model medical devices, such as stainless steel fiducials and 3D printed stents of complex geometry. Spin-coated fluorescent polymeric films loaded with a dye paired with the bulky centurion exhibit excellent biocompatibility and low toxicity. Moreover, counterion modified materials show much better stability against dye leakage in the presence of living cells and serum containing medium, compared to materials based on the dye with a small inorganic anion. Overall, by pushing the barriers of ACQ, our counterion approach emerges as a powerful tool to develop ultrabright fluorescent polymeric materials.

\section{INTRODUCTION}

Organic luminescent materials are used in many applications such as organic light emitting diodes $^{1}$ (OLEDs), security inks, ${ }^{2}$ waveguides ${ }^{3,4}$, sensing and imaging, ${ }^{5-8}$ etc. Efficient solid-state emission is strongly preferred for most of these applications..$^{9,10}$ In this respect luminescent polymeric thin films, coatings and nanofibers are of particular interest. Thin films have several advantages due to the ease of handling, higher stability and suitability for device-based applications. ${ }^{11}$ Fluorescent polymeric coatings can transform a non-fluorescent material into a fluorescent one simply depositing a micro-thin shell. ${ }^{12}$ On the other hand, nanofibers, generally prepared by electrospinning method, ${ }^{13}$ is one of the promising materials for variety of applications. Electrospun fibers possess large surface area, small diameter and a wide variety of polymers, 
ceramics can be electrospun into fibers. ${ }^{14-16}$ Electrospun fibers widely used in sensors, ${ }^{17-19}$ tissue engineering and drug delivery, ${ }^{20}$ wound healing ${ }^{21}$ and other medical applications. ${ }^{22}$

To implement luminescent capabilities, these materials are generally blended or conjugated with suitable dyes. However, organic dyes that are highly luminescent in dilute solutions often show poor emission in the solid state because of so-called aggregation-caused quenching (ACQ). ${ }^{9,10,23,24}$ Indeed, flat aromatic structure of organic dyes favors strong $\pi$ - $\pi$ stacking interaction forming weakly emissive or non-emissive H-aggregates. ${ }^{25}$ Due to ACQ effect, organic dyes are used in small concentrations as dopants or as dilute solutions which often leads to limited brightness, ${ }^{26,27}$ especially in case of thin films, coatings and nanofibers. Indeed, according to Lambert-Beer equation, for $10 \mu \mathrm{m}$ polymeric film loaded at $1 \mathrm{mM}$ concentration with a typical dye with extinction coefficient of $100,000 \mathrm{M}^{-1} \mathrm{~cm}^{-1}$ would exhibit an absorbance of 0.1 , which implies only $21 \%$ of light absorption, whereas for nanofibers of 100-500 nm diameter the absorbance would be 20-100 times lower.

Several approaches such as introduction of spiro-framework ${ }^{28,29}$, bulky group substitution ${ }^{30-32}$, J-aggregate formation ${ }^{33}$, introduction of non-planar groups ${ }^{34,35}$, supramolecular threading, ${ }^{36}$ etc., have been put forward to attenuate the ACQ phenomena and to improve the brightness of the luminescent materials both in the case of molecular dyes as well as in polymeric nanomaterials. Among the various approaches, aggregation induced emission (AIE), introduced by Tang and coworkers is most popular ${ }^{37}$. AIE molecules are poorly emissive in the solution state, whereas they show intense emission in the solid state due to phenomenon of restricted intramolecular rotation and proper dye-dye spatial arrangement ${ }^{27,38}$. AIE approach was successfully applied for development of a large variety of fluorescent materials ${ }^{26,35,38-40}$. Nevertheless, most of the reported modifications to achieve bright solid-state fluorescence are dye specific and require intense 
organic synthesis to alter the emission properties. Moreover, AIE approach is not well adapted for blending with polymers, which is important for fabrication of functional materials and coatings. ${ }^{41}$ A universal approach to transform the luminescence properties of solutions to solids is still lacking. Previously, we introduced hydrophobic counterions as an effective tool to minimize ACQ and improve the brightness of the dyes inside the polymeric nanoparticles. ${ }^{42-45}$ Bulky counterions play a role of a spacer between the dye molecules inside the nanoparticles and reduce the dye aggregation, whereas the hydrophobicity of the counterions helps in better dye encapsulation. ${ }^{42,43,46}$ Indeed, the quantum yield of the encapsulated dyes in polymeric NPs improved with the size and fluorination level of the counterions, ${ }^{42,46}$ providing proper dye-dye spacing for preventing ACQ. The bulky counterions ensured high fluorescence quantum yield of dyes (20-50 \%) for relatively high dye loading inside polymeric NPs (>200 mM vs polymer). ${ }^{47-49}$ Counterion approach was applied to develop NIR polymeric coatings with relatively low dye loading, which were validated for a various image-guided surgical applications. ${ }^{12,50}$ However, counterion approach has not been explored for development of bright fluorescent solid materials at high dye loading. Recently, Flood and co-workers proposed a supramolecular counterion approach coined as SMILES, where a cyanostar macrocycle in complex with an anion minimizes ACQ of dyes in pure salts and polymer blends. ${ }^{51}$ We asked a question whether counterion approach could be a universal tool to generate bright polymeric materials of any desired shape (e.g. films, coatings and nanofibers). In the present work, we introduce ultrabright fluorescent polymeric films, coatings and nanofibers based on a concept of ionic dye insulation with bulky hydrophobic counterions. Here, we address a fundamental problem of ACQ of organic dyes in polymeric materials at high loading. We show that bulky hydrophobic counterion can drastically improve brightness of cationic dyes in different bulk materials made of a biocompatible polymer in form 
of thin films, electrospun nanofibers and coatings. Counterion modified materials exhibited outstanding optical properties characterized by high brightness and quantum yield when compared to similar materials prepared with the parent dye with small inorganic counterion. Bulky counterion also allowed better dye encapsulation and higher dye loading in different material forms. New materials are biocompatible, non-toxic and stable in biological fluids. Finally, we demonstrated a proof-of-concept to fabricate bright electrospun with exceptional dye loading and fluorescent coatings on 3D printed medical objects.

\section{MATERIALS AND METHODS}

All the chemicals and solvents were purchased from either Sigma Aldrich or TCI or Carlo Erba and used as received without further purification. Membright 488 was prepared as previously described. ${ }^{52}$ 3,3'-Dioctadecyloxacarbocyanine perchlorate $\left(\mathrm{DiO} / \mathrm{ClO}_{4}\right)$ was from Sigma Aldrich. (1,1'-dioctadecyl-3,3,3',3'-tetramethylindodicarbocyanine chloride (DiD/Cl or F5-TPB) and blue cyanine iodide (BlueCy/I or F5-TPB) were prepared by following our previous reports. ${ }^{7,53}$ Fluorescence spectra were recorded on an Edinburg FS5 spectrofluorometer. All the spectra were corrected from the fluorescence of the corresponding blank (thin films or the fibers containing the PMMA polymer without dyes) and for the wavelength-dependent response function of the detector. Emission measurements were systematically done at room temperature, unless indicated otherwise. Absolute fluorescence quantum yields of the films and fibers were determined by integrating sphere method (SC30 integrating sphere, Edinburg Instruments). Scanning electron microscopy (SEM) images were acquired on Quanta TM 250 FEG scanning electron microscope (FEI, Edinhoven, Netherlands). Fluorescence microscopy images were acquired on Nikon Ti-E inverted microscope. Spin coating was performed on Laurell-WS-650 spin coater (Laurell 
Technologies). Electrospinning was performed on FLUIDNATEK LE-10 electrospinning equipment (Bioinicia). 3D printing was done with Form 3, 3D printer (Formlabs).

Spin coating. Spin coating was performed on Laurell spin coater. Stock solution of PMMA (150 $\mathrm{mg} / \mathrm{mL}, M w=120,000)$ was prepared by dissolving PMMA in acetonitrile for 18 hours. Coating solution was prepared by mixing PMMA (final concentration in solution: $1 / 5 / 10 \mathrm{mg} / \mathrm{mL}$ ) with dye salts such as R18/F5-TPB, R18/ClO4 (1 to $30 \mathrm{wt} \%$ with respect to the polymer) or BlueCy, DiO and DiD (with $\mathrm{I}^{-} / \mathrm{ClO}_{4} / \mathrm{Cl}$ or F5-TPB counterions) $5 \mathrm{wt} \%$ each in acetonitrile solvent. Spin coating was carried out in dynamic mode by depositing $30 / 50 \mu \mathrm{L}$ of the above solution on a clean circular glass substrate having the diameter $12 \mathrm{~mm}$ and $18 \mathrm{~mm}$ (for cell experiments). Spin coating was also carried out on quartz-coated glass substrates $(1 \mathrm{~cm} \times 1.5 \mathrm{~cm})$ by depositing $100 \mu \mathrm{L}$ of the above solution. Rotation speeds were maintained at $2000 \mathrm{rpm}$ for 30 seconds and further reduced to $500 \mathrm{rpm}$ for another 30 seconds. Emission response of the films were measured either by directly placing them in a solid state sample holder or by placing the coated glass substrates inside a $3 \mathrm{~cm}$ cuvette and the film was illuminated at the middle portion.

Electrospinning. Polymer solution for electrospinning was prepared by dissolving $500 \mathrm{mg}$ of PMMA $(25 \mathrm{wt} \%, \mathrm{Mw}=120,000)$ in $2 \mathrm{~mL}$ of DMF overnight. The resulting viscous solution was mixed with various concentration of $\mathbf{R} 18 / \mathbf{F 5}-\mathbf{T P B}$ and $\mathbf{R} 18 / \mathbf{C l O}_{4}$ ( 0.5 to $30 \mathrm{wt} \%$ with respect to the polymer concentration). Final concentration of the polymer in DMF was adjusted to $22 \mathrm{wt} \%$. Electrospinning was performed on a FLUIDNATEK LE-10 electrospinning equipment (Bioinicia). $1.5 \mathrm{~mL}$ of the above solution was loaded into a $5 \mathrm{~mL}$ syringe having $16 \mathrm{G}$ needle. A constant flow rate of $1.5 \mathrm{~mL} /$ hour was maintained throughout with the help of a syringe pump. A voltage of $18 \mathrm{KV}$ was applied to the syringe needle and an aluminum foil was used as the collector. The distance between the needle tip to the collector was adjusted to $15 \mathrm{~cm}$. The fiber mat obtained 
after the electrospinning was dried in an oven at $80^{\circ} \mathrm{C}$ for 2 hours. It was further dried under high vacuum overnight.

Absolute quantum yields measurements. Absolute quantum yields of the thin films and electrospun nanofibers were determined using an integration sphere (SC-30 Module, Edinburg Instruments). Thin films containing dyes such as R18/F5-TPB, R18/ClO4, BlueCy/F5-TPB, BlueCy/I, DiO/ClO4, DiO/F5-TPB, DiD/Cl, DiD/F5-TPB were prepared on a $12 \mathrm{~mm}$ glass substrate by spin-coating method. PMMA film without the dye was used as blank. Electrospun fiber mats were cut into $10 \mathrm{~mm}$ pieces and placed inside the sample holder. PMMA fibers without dye was used as reference. Absolute quantum yields were measured by direct excitation method with 5 and $0.7 \mathrm{~nm}$ excitation and emission slit widths respectively.

Fluorescence imager setup. A home-built fluorescence imaging system was utilized to capture the fluorescence images of $\mathrm{DiD} / \mathrm{Cl}, \mathrm{DiD} / \mathrm{F} 5-\mathrm{TPB}$ thin films and electrospun fiber mats. Imaging setup consists of a 530/630 nm LED array lamp (ThorLabs/ Prophotonix) as excitation source and a motorized filter wheel (ThorLabs) equipped with 600/52 and 650/90 band-pass filters (BrightLine HC, AHF) to collect the emitted light. Scientific CMOS (sCMOS) camera (ThorLabs) was used to capture the images. All the images were acquired from the camera at room temperature with 50/150 ms exposure time using ThorCam software. ImageJ software was utilized to analyze the images.

SEM imaging. For SEM imaging, PMMA electrospun mats loaded either with $5 \mathrm{wt} \%$ R18/F5TPB or $\mathbf{R 1 8} / \mathrm{ClO}_{4}$ were used. Samples were sputter-coated with Palladium under Argon atmosphere for 15 minutes. SEM images were acquired by Quanta TM 250 FEG scanning electron microscope (FEI, Edinhoven, Netherlands) using 7.5 KV beam voltage. Fiber diameters were 
determined by ImageJ software. 150 individual fibers were analyzed for each sample to determine the average diameter of elctrospun fibers.

Biocompatibility assessment and fluorescence microscopy. Biocompatibility of the thin films were evaluated by culturing the HeLa cells on the spin-coated glass substrate. First, the $18 \mathrm{~mm}$ circular glass substrates were spin-coated with PMMA polymer having either and R18/F5-TPB or R18/CIO4. An empty glass coverslip without the coating was used as the control. Thin films were sterilized by washing two times with 70\% ethanol and dried. HeLa cells (ATCC ${ }^{\circledR}$ CCL-2) were grown in Dulbecco's modified Eagle medium (DMEM, Gibco-Invitrogen), supplemented with $10 \%$ fetal bovine serum (FBS, Lonza) and 1\% antibiotic solution (penicillin-streptomycin, GibcoInvitrogen) at $37^{\circ} \mathrm{C}$ in humidified atmosphere containing $5 \% \mathrm{CO}_{2}$. The films were placed on to a chambered cover glass $\left(\mathrm{IBiDi}^{\circledR}\right)$ and the cells were seeded on the films at a density of $1 \times 10^{5}$ cells/well, $24 \mathrm{~h}$ before the microscopy measurement. For imaging, the medium was removed and the remaining attached cells were washed 3 times with PBS (Gibco-Invitrogen) and the cells were stained with membrane marker Membright-488 (50 nM) in HBSS for 5 minutes in dark. Fluorescence imaging was performed by Nikon Ti-E inverted microscope with 60x in spinning disk mode using X-light (CrestOptics) module and laser excitation (Oxxius). Membright-488 was excited with $488 \mathrm{~nm}$ laser and the emission was collected in the green channel with 531/40 bandpass filter. and R18/F5-TPB and R18/ClO 4 films were excited with $532 \mathrm{~nm}$ laser and the emission was collected in red channel with 600/50 band-pass filter. ImageJ software was used to process the fluorescence images.

3D-printing. Form 3, 3D printer (Formlabs) was used for 3D printing. Stent prototype $(1 \mathrm{~cm}$ width, $3 \mathrm{~cm}$ height) that mimics the vascular medical stents was designed with FreeCAD parametric 3D modeler software (STL file is available upon request). Clear V4 resin (Formlabs) 
was used for 3D printing. After the 3D printing, polymer stents were rinsed with isopropyl alcohol to get rid of the excess resin and cured under UV light for 30 minutes.

Method for coating steel wires and 3D-printed stents. Coating formulation was prepared by mixing the PMMA polymer, $M w=120,000(100 / 30 \mathrm{mg} / \mathrm{mL}$ for steel wires and polymer stents respectively) and $\mathbf{R 1 8} / \mathbf{F 5}-\mathbf{T P B}$ or $\mathbf{R} 18 / \mathbf{C l O}_{4}(0.1$ or $5 \mathrm{wt} \%$ with respect to polymer) in acetonitrile solvent. Stainless steel wires having a diameter of $0.1 \mathrm{~mm}$ was cut into $1 \mathrm{~cm}$ pieces. Steel wires were cleaned with water and ethanol by sonication for 15 minutes and dried. Wires were dipcoated in the formulation and dried under fume hood for 15 minutes. Dip-coating step was repeated 2 times in order to have sufficiently thick and bright fluorescent coating layer. 3D-printed polymer stents were dip-coated in the same manner as explained above. Fluorescence images of the steel wires were captured in a home-built imaging set up. Images were analyzed with ImageJ software. Coated stents were observed under $365 \mathrm{~nm}$ UV lamp and images were captured with a camera.

Dye leakage study in serum. For dye leakage studies in serum, spin-coated thin films containing $\mathbf{R 1 8} / \mathbf{C l O}_{4}$ and $\mathbf{R 1 8} / \mathbf{F 5}-\mathbf{T P B}$ were placed in $1 \mathrm{~mL}$ of water containing $10 \mathrm{vol} \%$ fetal bovine serum (FBS). The samples were incubated at $37^{\circ} \mathrm{C}$ for 2 or 24 hours. Absorption and emission spectra of the serum samples were measured after 2 and $24 \mathrm{~h}$ incubation. Serum sample without coating film was used as a control. Absorption and emission spectra of blank serum sample was compared with those incubated with $\mathrm{R} 18 / \mathrm{ClO}_{4}$ or $\mathbf{R} 18 / \mathbf{F 5}-\mathrm{TPB}$ films to determine the dye leakage.

Toxicity assessment of the films by WST- 1 assay. Cytotoxicity of the $\mathrm{R18} / \mathrm{ClO}_{4}$ and $\mathrm{R18} / \mathrm{F5}$ TPB spin coated films were determined by WST-1 assay. This assay is based on the cleavage of tetrazolium salt of WST-1 in to water soluble formazan by mitochondrial dehydrogenases present in the living cells. The formazan dye produced by the activity of the living cells can be quantified 
by measuring the absorbance at $440 \mathrm{~nm}$. First, the thin films were prepared by spin-coating on 12 mm glass substrates. Films were sterilized by washing two times with $70 \%$ ethanol. After drying, the substrates were placed in a 24 well plate. A glass substrate without any coating and the substrate coated with only the polymer was used as control. HeLa cells were seeded on the substrates (6 repeats per each dye) at a density of $3 \times 10^{4}$ cells/well and incubated for $24 \mathrm{~h}$ at $37^{\circ} \mathrm{C}$ in DMEM medium. Cells were also treated with DMEM containing $0.1 \%$ Triton-X 100 as a positive control of cytotoxicity. After $24 \mathrm{~h}$, WST-1 reagent ( $5 \mu \mathrm{L} /$ well) was added to each well containing $200 \mu \mathrm{L}$ DMEM medium. The plates were maintained at $37^{\circ} \mathrm{C}$ for $4 \mathrm{~h}$. Then, $200 \mu \mathrm{L}$ of DMEM from each well was transferred to a 96-well plate and the absorbance was measured at $440 \mathrm{~nm}$ and $630 \mathrm{~nm}$. Percentage of viable cells with respect to control cells was calculated.

\section{RESULTS AND DISCUSSION}

Material fabrication and photophysical evaluation. As a control dye, we used commercial rhodamine octadecyl ester perchlorate $\left(\mathbf{R 1 8} / \mathbf{C l O}_{4}\right)$, which was synthesized as reported elsewhere. ${ }^{54}$ Tetrakis (pentafluorophenyl)borate (F5-TPB) was selected as a bulky hydrophobic counterion, because it has shown effective to prevent ACQ in polymeric NPs. ${ }^{24,42,44}$ The perchlorate counterion in $\mathbf{R} 18 / \mathbf{C l O}_{4}$ was replaced with F5-TPB by an ion-exchange method ${ }^{42}$ followed by purification by chromatography to yield R18/F5-TPB (Scheme 1 and SI). Rhodamine dyes (both $\mathbf{R 1 8} / \mathrm{ClO}_{4}$ and $\mathbf{R 1 8} / \mathbf{F 5}-\mathbf{T P B}$ ) were mixed separately with a biocompatible polymer, poly(methyl methacrylate) (PMMA) in acetonitrile solvent and transformed into different material forms such as thin films, nanofibers and coatings by various techniques (Scheme 1). 
a)

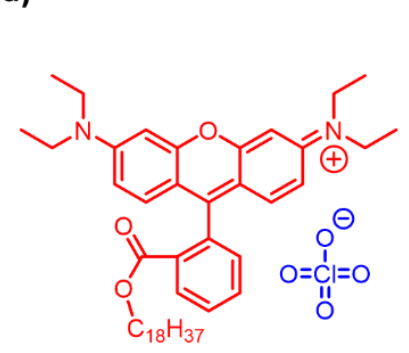
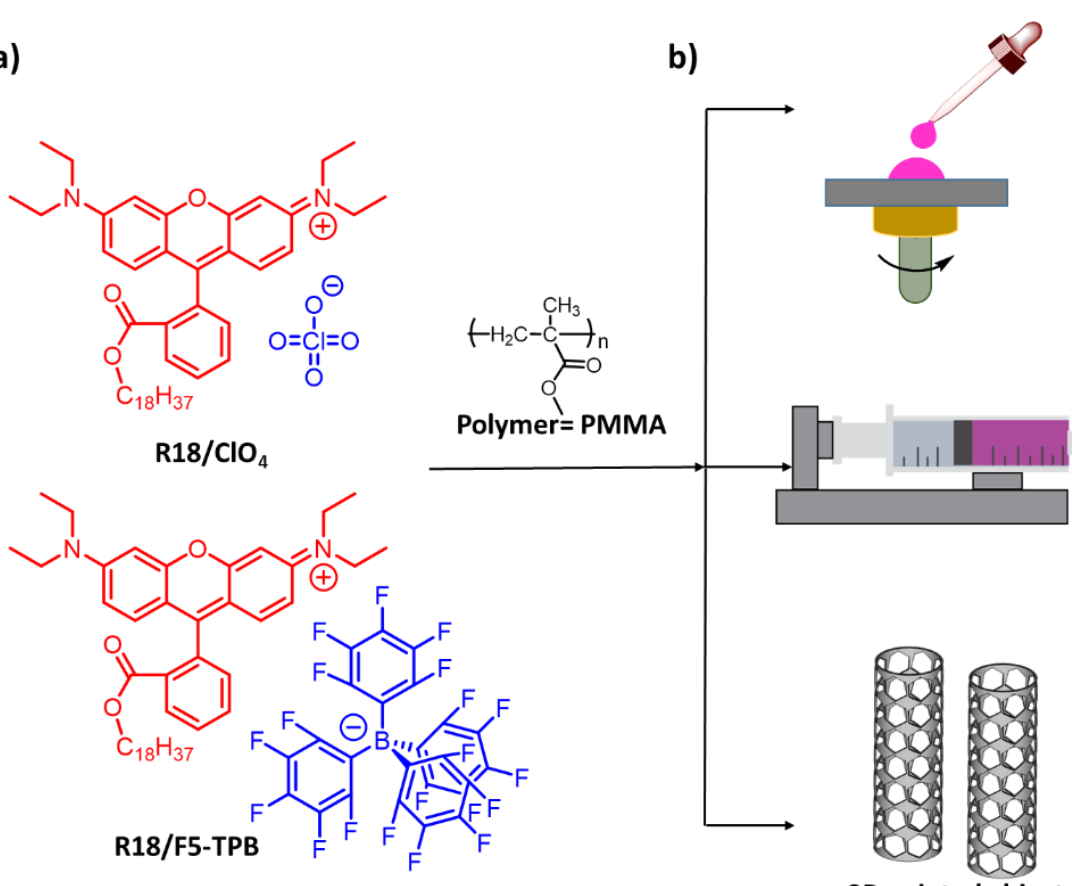

b)

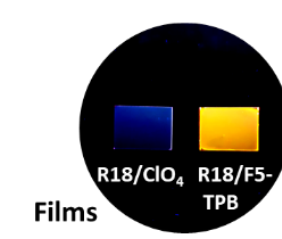

R18/F5-TPB

Scheme 1. a) Dye salts: dye is shown in red, while the counterion is shown in blue. b) Schematic overview of the transformation of dyes with a biocompatible polymer into various material forms such as films, fibers and coatings, their corresponding fluorescence images.

Thin films of R18/ClO 4 and R18/F5-TPB were prepared by spin coating on the glass substrate. Initially, different concentrations of the PMMA $(1 / 5 / 10 \mathrm{mg} / \mathrm{mL})$ were tested by keeping the dye loading constant ( $5 \mathrm{wt} \%$ with respect to PMMA). Fluorescence intensity form the films increased with polymer concentration (Figure S1), which was clearly related to the increase in the film thickness. Therefore, we selected an intermediate polymer concentration $(5 \mathrm{mg} / \mathrm{mL})$ for further studies to avoid any potential inner filter effect caused by thick film at high dye loading. Although the absorption maxima for $\mathrm{R18} / \mathrm{ClO}_{4}$ and $\mathbf{R 1 8} / \mathbf{F 5}-\mathrm{TPB}$ films were similar (Figure 1a and Figure S1a-c), R18/F5-TPB films showed narrower absorption band with less intense short-wavelength shoulder (Figure 1a and Figure S1a-c), indicating less pronounced dye aggregation. Thin films containing R18/F5-TPB showed much higher fluorescence intensity compared to $\mathbf{R 1 8} / \mathrm{ClO}_{4}$ films 
at all the tested polymer concentrations (Figure 1b, S1(d-f) and S2). Photos of representative spincoated thin films confirmed the striking effect of the counterion: R18/F5-TPB films displayed a bright red emission, whereas $\mathbf{R 1 8} / \mathbf{C l O}_{4}$ film appeared dark (Figure $1 \mathrm{~b}$ inset). Then, the PMMA concentration was fixed to optimum $5 \mathrm{mg} / \mathrm{mL}$ and the effect of dye loading $(0.1-20 \mathrm{wt} \%)$ on the fluorescence intensity was studied (Figure 1c). R18/ClO4 showed weak fluorescence at low loading ( 0.1 to $1 \mathrm{wt} \%)$ and its fluorescence was almost completely quenched at higher loadings ( $>5 \mathrm{wt} \%$ ) (Figure 1c), suggesting the strong ACQ effect in thin films containing $\mathbf{R} 18 / \mathbf{C l O}_{4}$. On the other hand, R18/F5-TPB films systematically showed very high fluorescence intensity at different loadings and their fluorescence intensity increased with increase in the dye content. The absolute quantum yield (QY) values, measured by an integration sphere method (see SI for details), revealed remarkably higher values for $\mathbf{R} 18 / \mathbf{F 5}-\mathbf{T P B}$ films compared to $\mathbf{R 1 8} / \mathrm{ClO}_{4}$ at all the tested dye loadings (Figure 1d and Table S1). At $20 \mathrm{wt} \%$ dye loading, R18/F5-TPB thin films showed more than 130-fold higher QY (38 $\pm 4 \%)$ than R18/CIO4 $(0.29 \pm 0.09 \%)$. Moreover, R18/F5-TPB maintained a high QY of $33 \pm 2 \%$ even at $30 \mathrm{wt} \%$ loading (Figure $1 \mathrm{~d}$ and Table S1), whereas for $\mathbf{R 1 8} / \mathrm{ClO}_{4}$ the fluorescence signal was no more detectable. These studies clearly suggest that in R18/F5-TPB thin films, bulky counterions play a major role in separating the dyes from $\pi-\pi$ stacking interaction and preventing them from ACQ effect, whereas in the case of $\mathbf{R} 18 / \mathbf{C l O}_{4}$ thin films, small perchlorate counterions cannot prevent dye aggregation, thus leading to fluorescence quenching. Moreover, bulky counterions allows higher dye loading in polymer films which otherwise, is difficult to achieve with the dyes having smaller counterions (like $\left.-\mathrm{ClO}_{4}\right)$ without altering the optical properties. This material is expected to present an outstanding brightness, because here we achieved unprecedented dye loading in a polymer film while preserving high QY 
values. In one of the brightest fluorescent materials recently reported by Flood and coworkers using SMILES method, a maximum of $10 \mathrm{wt} \%$ dye loading was attained. ${ }^{51}$
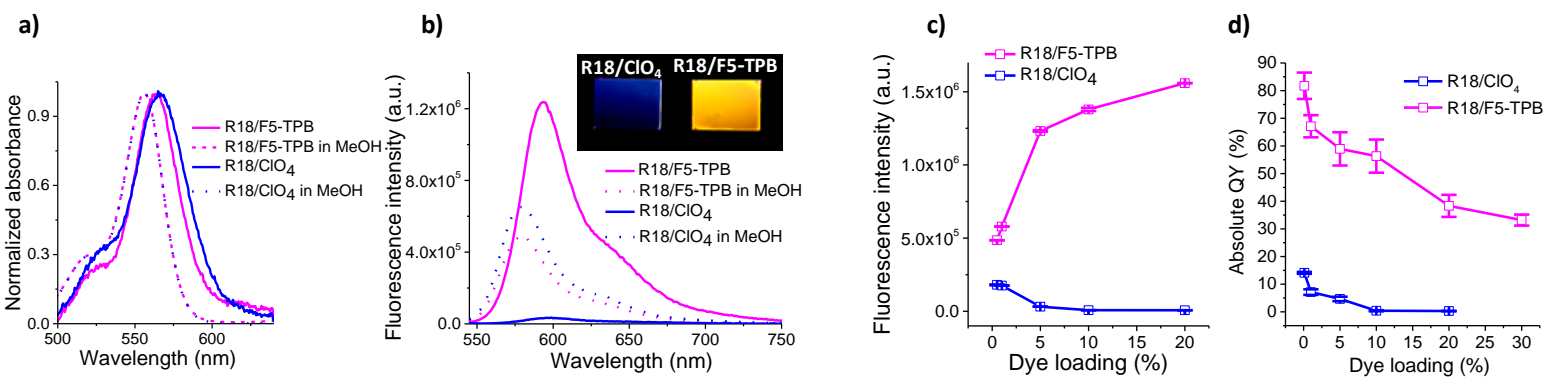

Figure 1. Photophysical properties of the thin films. (a) Absorption spectra of PMMA thin films containing R18/ClO4 and R18/F5-TPB (5 wt $\%$ each). (b) Corresponding emission spectra of thin films. Dotted lines in a and b represent the absorption and emission spectra, respectively, of R18/ClO4 and R18/F5-TPB $(1 \mu \mathrm{M})$ in Methanol. Inset in figure $b$ are the representative fluorescence images of the spin-coated thin films captured with a camera under UV light illumination and processed with ImageJ software. (c) Fluorescence intensity of the thin films at different dye loading. (d) Absolute quantum yield values of thin films at different dye loading. Note: Absolute quantum yield for $\mathbf{R 1 8} / \mathbf{C l O}_{4}$ at $30 \mathrm{wt} \%$ loading was not determined because of the very low signal to noise ratio.

To verify the universality of this approach, we selected a series of cationic cyanine dyes having fluorescence emission from blue to far-red spectral region. PMMA thin films containing BlueCy, $\mathrm{DiO}$ and DiD dyes (5 wt\% each) with small counterions $\left(\mathrm{I}^{-} / \mathrm{ClO}_{4}-\mathrm{Cl}^{-}\right)$and bulky F5-TPB counterion were prepared by spin coating on glass substrate. Thin films containing dyes with F5TPB counterion showed systematically higher fluorescence intensity compared to the respective thin films with smaller counterions (Figure 2 a-c). Images of the thin films containing BlueCy, DiO and DiD with F5-TPB displayed bright blue, green and red emission, respectively (insets in 
Figure $2 \mathrm{a}-\mathrm{c}$ ), whereas the films with small counterions were mostly non-emissive suggesting the strong ACQ effect. It should be noted that, a white tinge in the thin film of $\mathrm{DiO} / \mathrm{ClO}_{4}$ could be due to the formation of aggregates with broad emission band, Figure $2 \mathrm{~b}$. In case of $\mathrm{DiD}$, the emission maximum was observed in the near-infrared region $(711 \mathrm{~nm})$, which was significantly redshifted compared to that in methanol (667 nm, Figure S3). Moreover, absolute QY values for thin films containing dyes with F5-TPB were much higher compared to those with small counterions (Figure $2 \mathrm{~d}$ and Table S2). These studies confirm that the counterion approach can be extended to other cationic dyes to produce bright fluorescent materials of any color from blue to near-infrared.
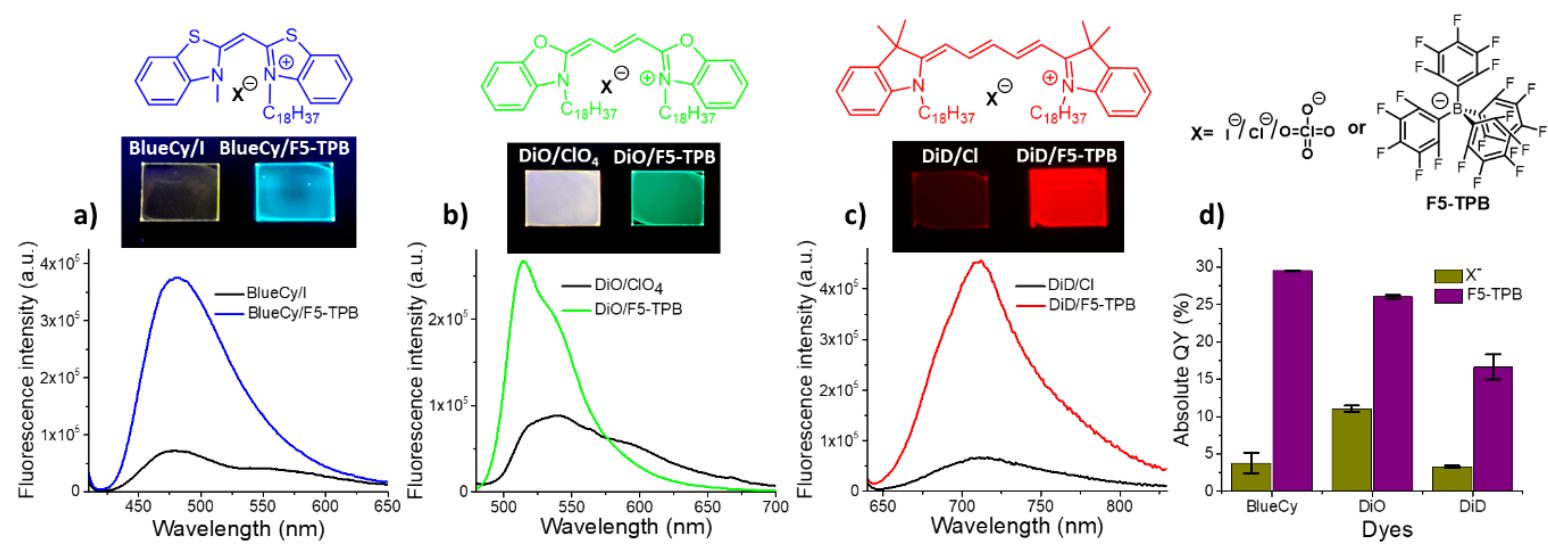

Figure 2. Photophysical properties of PMMA thin films containing different dyes ( $5 \mathrm{wt} \%$ each) with or without bulky counterion. Emission spectra of thin films containing (a) BlueCy, (b) DiO and (c) DiD with small counterions $\left(\mathrm{I}^{-} / \mathrm{ClO}_{4} / \mathrm{Cl}^{-}\right)$or with F5-TPB. Insets in panels (a) and (b) are the representative fluorescence images (photos) of the spin-coated thin films under UV light illumination. In panel (c) DiD-based thin films were imaged with a home-built imager setup (630 $\mathrm{nm}$ excitation with 690/50 $\mathrm{nm}$ band pass emission filter). (d) Absolute quantum yield values of thin films containing different dyes with small counterions $\left(\mathrm{I}^{-} / \mathrm{ClO}_{4}{ }^{-} / \mathrm{Cl}^{-}\right)$or with F5-TPB. Error bars are standard deviation of the mean $(\mathrm{n}=2)$. 
Biocompatibility, dye leakage studies and toxicity assessment. We have further evaluated the biocompatibility of the thin films by culturing HeLa cells on the spin-coated PMMA films containing $5 \mathrm{wt} \% \mathbf{R 1 8} / \mathbf{F 5}-\mathbf{T P B}$ and $\mathbf{R 1 8} / \mathbf{C l O}_{4}$. After 24 hours of incubation, the plasma membrane of HeLa cells was labelled with membrane marker, Membright-488. Fluorescence microscopy images of HeLa cells suggested that the cells were nicely adhered and proliferated on thin films containing R18/F5-TPB and $\mathbf{R 1 8} / \mathbf{C l O}_{4}$ (Figure 3), similar to the cells grown on the plain glass coverslips (Figure S4).

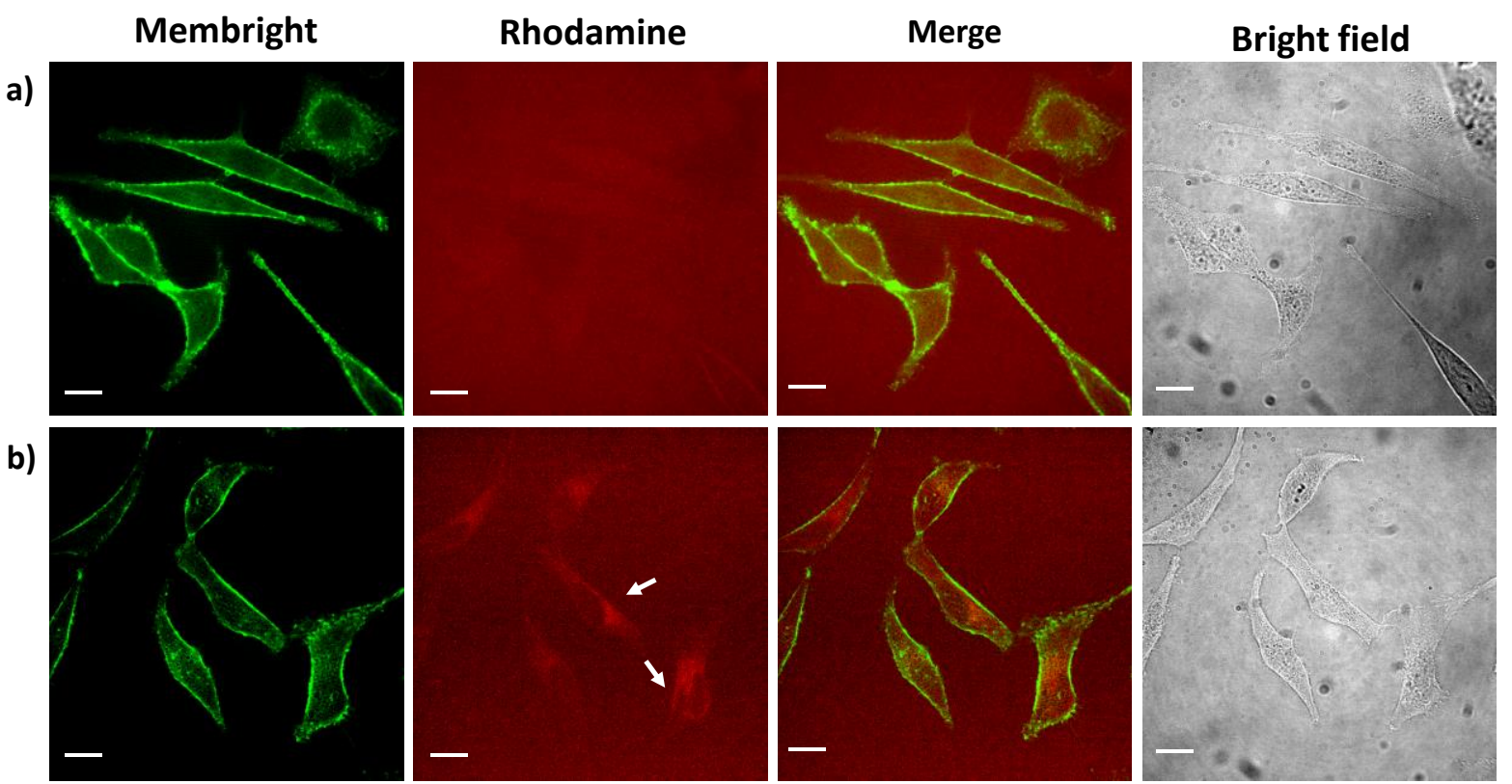

Figure 3. Fluorescence microscopy images of HeLa cells cultured on spin-coated PMMA thin films containing R18/F5-TPB (a) and R18/ClO 4 (b) (5 wt \% each). Plasma membrane was stained with Membright-488 (100 nM). Scale bar $20 \mu \mathrm{m}$.

Moreover, HeLa cells showed prominent plasma membrane (stained in green) and regular morphology. These observations suggest that the cells are healthy on thin films without any signs of toxicity. However, the analysis of the rhodamine channel and overlay images clearly indicates the dye leakage from the thin films containing $\mathbf{R 1 8} / \mathbf{C l O}_{4}$ (Figure 3b, indicated by the white 
arrows). In the case of R18/F5-TPB thin films, the red fluorescence from cells was almost negligible (Figure 3a), suggesting negligible dye leakage. The observed faint cell structures in the red channel in this case looked rather like optical effect because it reproduced the shape of the cells, being different from the characteristic intracellular standing observed for leaked R18 shown in Figure 3b. Dyes with smaller hydrophilic counterions (like $\mathrm{ClO}_{4}^{-}$) tend to leach out from the surface in aqueous medium whereas the bulky hydrophobic counterions helps in better encapsulation and hence, no leakage was observed. This is similar to our previous observations in nanoparticles and NIR coatings. ${ }^{12,44}$ Additionally, we have evaluated the dye leakage from PMMA films loaded with R18/F5-TPB and $\mathbf{R 1 8} / \mathbf{C l O}_{4}$ (5 wt\%) in model biological medium containing fetal bovine serum (FBS) by recording absorption and emission spectra after $2 \mathrm{~h}$ and $24 \mathrm{~h}$ incubation at $37^{\circ} \mathrm{C}$. Interestingly, when compared to the blank serum samples, samples that were incubated with $\mathbf{R 1 8} / \mathrm{ClO}_{4}$ films showed significant enhancement in the dye absorption already within $2 \mathrm{~h}$ incubation (Figure $4 \mathrm{a}$ ), suggesting the dye leakage into the serum. By contrast, serum samples containing R18/F5-TPB did not show any significant change in the absorption (Figure 4a). This observation was further supported by the remarkable increase in the fluorescence intensity from serum samples incubated with $\mathbf{R} 18 / \mathbf{C l O}_{4}$ films but no such change was observed for the serum samples incubated with R18/F5-TPB films for both 2 and 24h (Figure 4b). Much higher stability of $\mathbf{R} \mathbf{1 8} / \mathbf{F 5}-\mathbf{T P B}$ thin films compared to $\mathbf{R 1 8} / \mathbf{C l O}_{4}$ films was confirmed for preparations with two different polymer concentrations (1 $\mathrm{mg} / \mathrm{mL}$ and $5 \mathrm{mg} / \mathrm{mL}$ PMMA) by maintaining the constant dye loading (Figure S5). These studies further confirm that the bulky hydrophobic counterion prevents cationic dyes from leaching into biological medium. Additionally, we have performed the cytotoxicity assay by WST-1 reagent (2-(4-iodophenyl)-3(4-nitophenyl)-5-(2,4-disulfophenyl)-2 H-tetrazolium salt) to assess the potential toxicity of the 
thin films containing R18/F5-TPB and R18/CIO4 along with bare PMMA films. Thin films with different dye loadings were prepared and HeLa cells were cultured on it for 24 hours (see SI for details). More than $90 \%$ cell survival was observed for all the tested conditions, similar to the data on the bare glass, indicating no signs of cytotoxicity of our films (Figure 4c). This further confirms the biocompatibility of these materials.

a)

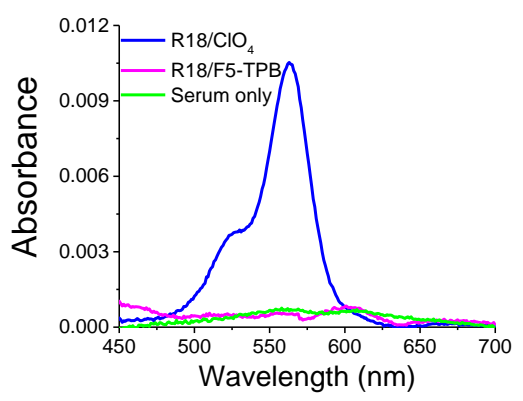

b)

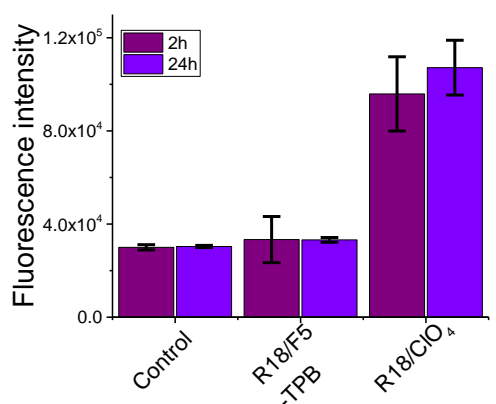

c)

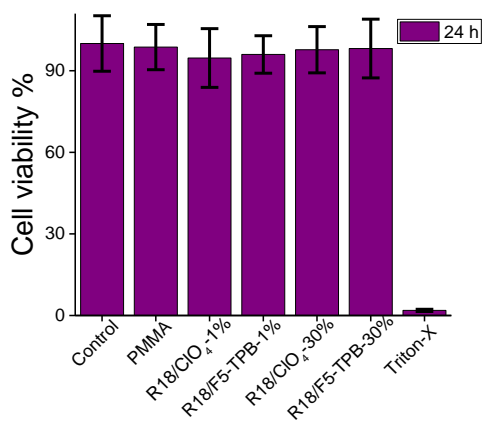

Figure 4. Dye leakage studies in 10\% fetal bovine serum in water. (a) Absorption spectra of the serum samples after $2 \mathrm{~h}$ incubation at $37^{\circ} \mathrm{C}$ with $\mathbf{R} 18 / \mathbf{C l O}_{4}$ and $\mathbf{R} 18 / \mathbf{F 5}-\mathbf{T P B}$ (5 wt $\%$ each) thin films. (b) Emission response of serum samples after $2 \mathrm{~h}$ and $24 \mathrm{~h}$ incubation at $37^{\circ} \mathrm{C}$ with $\mathbf{R 1 8} / \mathbf{C l O}_{4}$ and R18/F5-TPB thin films. Error bars are standard deviation of the mean $(n=3)$. (c) WST-1 cytotoxicity evaluation after $24 \mathrm{~h}$ cell seeding on the substrates containing PMMA polymer films and $\mathbf{R 1 8} / \mathrm{ClO}_{4}$ and R18/F5-TPB dye loaded films. Error bars are standard deviation of the mean $(n=6)$.

Fabrication of dye loaded electrospun fibers and photophyical studies. Next, we transformed these dyes into fluorescent nanofibrous materials by electrospinning technique. Biocompatible PMMA was used as the polymer matrix. Spinning parameters were optimized (see SI) to obtain smooth, continuous fibers. To this end, we prepared the nanofibers either with PMMA polymer alone or with the polymer loaded with R18/F5-TPB and R18/ClO4. Representative scanning electron microscope (SEM) images of the electrospun fibers showed randomly oriented nanofibers 
with smooth surfaces (Figure 5a-c and Figure S6). Nanofibers prepared with only PMMA polymer showed an average diameter of $364 \pm 20 \mathrm{~nm}$, whereas fibers loaded with $5 \mathrm{wt} \%$ of R18/F5-TPB and $\mathbf{R 1 8} / \mathbf{C l O}_{4}$ showed a slightly larger diameter of $429 \pm 18 \mathrm{~nm}$ and $439 \pm 20 \mathrm{~nm}$ respectively (Figure 5d-f).

a)
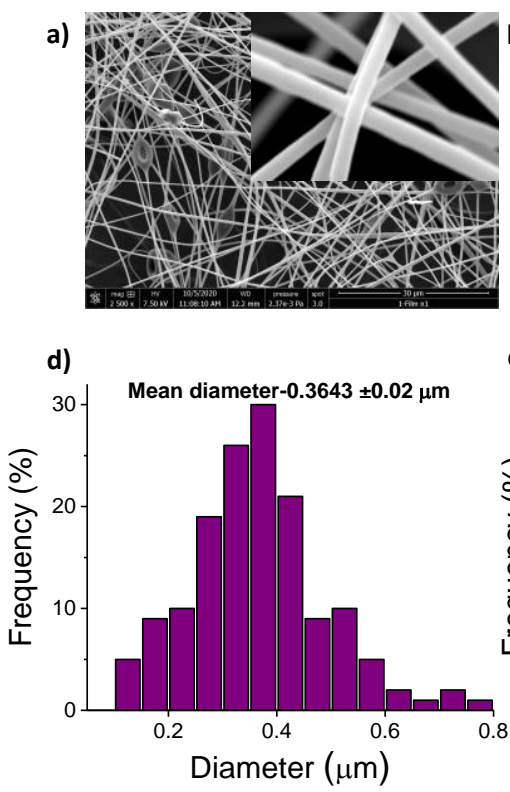

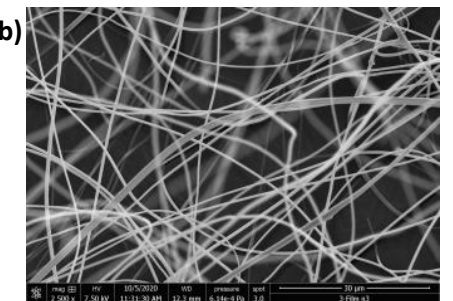

e)

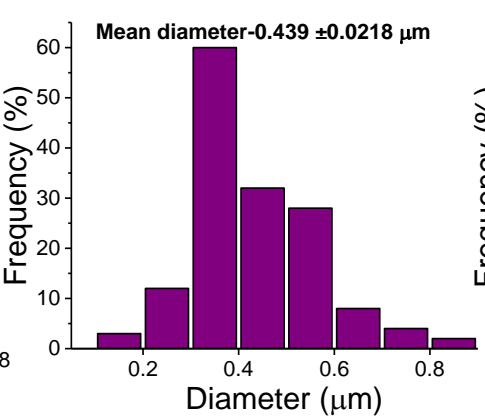

f)
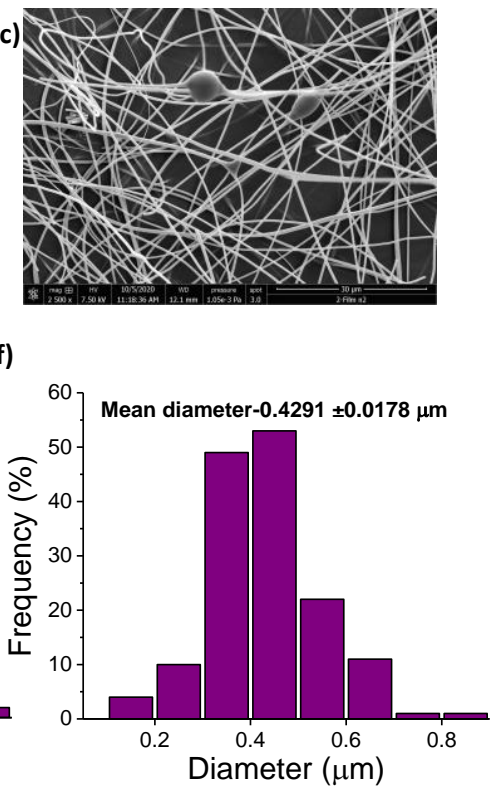

Figure 5. SEM micrographs of electrospun (a) PMMA polymer fibers alone. Inset in (a) shows an enlarged portion of the fibers. (b) PMMA fibers loaded with $5 \mathrm{wt} \% \mathbf{R} 18 / \mathbf{C l O}_{4}$. (c) PMMA fibers loaded with $5 \mathrm{wt} \%$ R18/F5-TPB. (d-f) Represents corresponding size distribution of fibers of a-c respectively.

Emission spectra of the electrospun fibers at different loading of R18/F5-TPB and R18/ClO 4 were characterized by a single band centered around $600 \mathrm{~nm}$. Already at $0.5 \mathrm{wt} \%$ dye loading, fluorescence intensity was significantly higher for the R18/F5-TPB loaded fibers compared $\mathbf{R 1 8} / \mathbf{C l O}_{4}$ fibers (Figure $6 \mathrm{a}$ ). At $5 \mathrm{wt} \%$ loading of $\mathbf{R 1 8} / \mathrm{ClO}_{4}$, the emission band almost vanished indicating severe ACQ, whereas in the case of R18/F5-TPB loaded fibers, a strong emission was observed (Figure 6b). Remarkably, the emission intensity of R18/F5-TPB fibers was $>290$ fold 
higher than the $\mathbf{R 1 8} / \mathbf{C l O}_{4}$ fibers with this dye loading. Using home-built imager set up (see SI), we confirmed a bright emission from R18/F5-TPB loaded nanofiber mats, almost negligible emission of R18/ClO4 fiber mats, especially at higher (5 wt\%) loading (Figure 6c). Optical microscopy images of electrospun nanofibers prepared with $5 \mathrm{wt} \% \mathbf{R} 18 / \mathbf{F 5}-\mathbf{T P B}$ dye loading showed they are indeed fluorescent and the staining is homogenously distributed without apparent dots or irregularities (Figure 6d). Moreover, the absolute quantum yield values for the R18/F5TPB loaded electrospun fibers were significantly higher compared to the $\mathbf{R} 18 / \mathbf{C l O}_{4}$ loaded fibers (Figure $6 \mathrm{e}$ and Table S3): $57 \pm 2 \%$ vs $2.5 \pm 0.5 \%$ at $5 \mathrm{wt} \%$ dye loading. Interestingly, R18/F5TPB loaded electrospun fiber mats showed strong fluorescence emission even at $30 \mathrm{wt} \%$ dye loading (Figure S6), with QY values of $31 \pm 0.5 \%$ (Figure 6e and Table S3). Previous reports on dye-doped nanofibers used rhodamine $6 \mathrm{G}$ dye, which allowed only $0.3 \mathrm{wt} \%(6 \mathrm{mM})^{55}$ and $0.1 \mathrm{wt} \%$ $(2 \mathrm{mM})^{56}$ dye doping, probably because of a significant aggregation of this dye starting from 6 $\mathrm{mM}$ loading. ${ }^{57}$ Moreover, a recent study using rhodamine, fluorescein and acridine dyes showed significant quenching beyond $0.5 \mathrm{wt} \%$ loading in the polymeric nanofibers. ${ }^{58}$ Owing to the bulky counterion approach, we achieved nearly 100 -fold stronger loading of a rhodamine derivative, while preserving minimal ACQ and high QY values, which corresponds to brightness improvement by nearly two orders of magnitude.
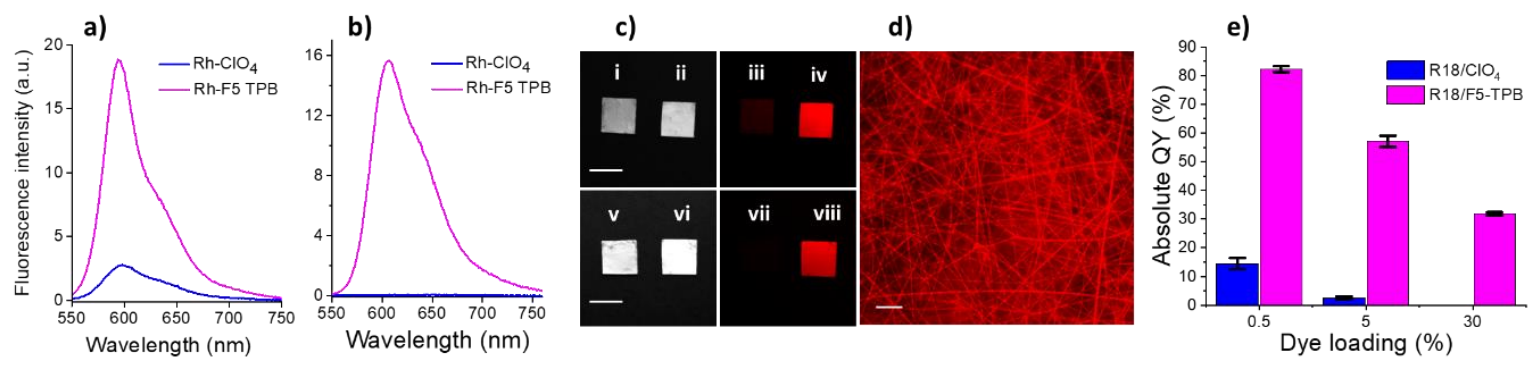

Figure 6. Characterization of fluorescent electrospun nanofibers. (a) Emission spectra of electrospun nanofibers prepared with $0.5 \mathrm{wt} \%$ dye loading. (b) Emission spectra of electrospun 
nanofibers prepared with $5 \mathrm{wt} \%$ dye loading. (c) Upper panels: represents the white light (i, ii) and fluorescence (iii, iv) images of electrospun fiber mats loaded at $0.5 \mathrm{wt} \%$ with $\mathbf{R} 18 / \mathbf{C l O}_{4}$ (i,iii) and R18/F5-TPB (ii,iv). Bottom panels: represents the white light (v, vi) and fluorescence (vii, viii) images of electrospun nanofiber mats loaded at $5 \mathrm{wt} \%$ with $\mathbf{R 1 8} / \mathbf{C l O}_{4}$ (v,vii) and R18/F5-TPB (vi,viii). Scale bar, $1 \mathrm{~cm}$. (d) Fluorescence microscopy image of R18/F5-TPB (5 wt\%) loaded fibers. Scale bar, $10 \mu \mathrm{m}$. Fluorescence images were captured with a home-built imager setup. (e) Absolute quantum yield values of electrospun nanofibers at different dye loading (Note: Electrospun nanofibers loaded with $\mathbf{R} 18 / \mathbf{C l O}_{4}$ at 30 wt $\%$ were not prepared). Error bars are standard deviation of the mean $(n=2)$.

Coatings on steel wires and 3D printed objects. Finally, we explored the capacity of our polymer blend with the rhodamine dye salt to be used as a coating for different surfaces and shapes. According to our previous studies, microns-thick coatings can be obtained by dip-coating of materials with a PMMA solution in acetonitrile. ${ }^{12}$

a)

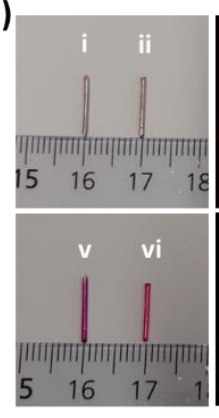

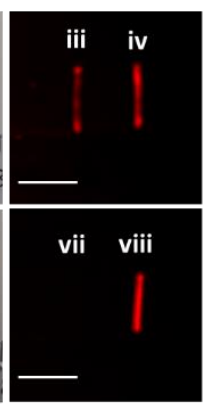

b)

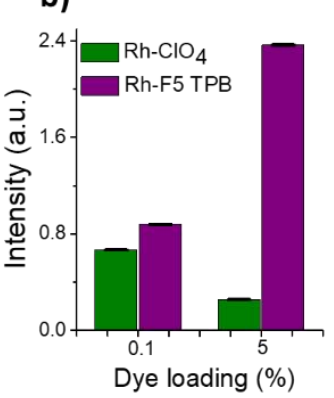

c)

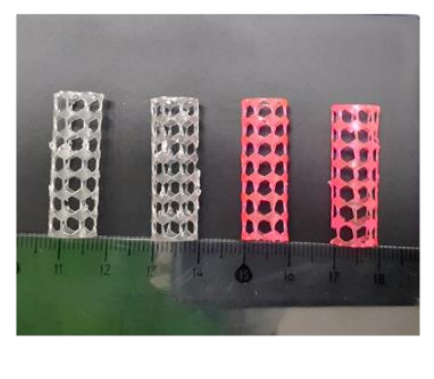

d)

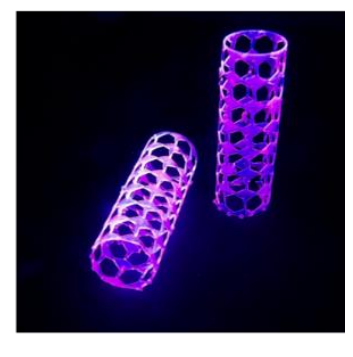

Figure 7. Application of PMMA blends with rhodamine dye salts as coatings of different objects of medical relevance. (a) Upper panels: represents the white light (i, ii) and fluorescence (iii, iv) images of the steel wires dip-coated in a PMMA solution containing $0.1 \mathrm{wt} \%$ of $\mathbf{R} \mathbf{1 8} / \mathbf{C l O}_{4}$ (i, iii) and R18/F5-TPB (ii, iv). Bottom panels: the same as top panels but at $5 \mathrm{wt} \%$ dye loading of R18/ClO4 (v, vii) and R18/F5-TPB (vi, viii). Scale bar is $1 \mathrm{~cm}$. (b) Fluorescence intensity analysis 
of the coated steel wires. (c) 3D-printed polymer medical stent mimics coated with R18/F5-TPB (5 wt\%) doped PMMA. (d) Fluorescence images of coated stents observed under $365 \mathrm{~nm}$ UV lamp.

Using this method, we first coated stainless steel wires with PMMA containing different concentration of $\mathbf{R 1 8} / \mathbf{C l O}_{4}$ and $\mathbf{R 1 8} / \mathbf{F 5}-\mathbf{T P B}$ dyes ( 0.1 and $5 \mathrm{wt} \%$ each). According to fluorescence images, at low dye loading $(0.1 \mathrm{wt} \%)$, both $\mathbf{R 1 8} / \mathrm{ClO}_{4}$ and R18/F5-TPB showed detectable but rather heterogeneous fluorescence along the wire (Figure 7a top panels). Interestingly, at higher dye loading ( $5 \mathrm{wt} \%$ ), complete fluorescence quenching was observed for the steel wires coated with $\mathbf{R 1 8} / \mathbf{C l O}_{4} / \mathrm{PMMA}$, whereas a strong emission was observed for those containing R18/F5-TPB (Figure 7a bottom panels). This observation was further supported by the fluorescence intensity analysis, wherein a clear superiority of the R18/F5-TPB coating was observed (Figure 7b).

Optical coatings on medical devices are valuable tools in the image-guided surgery ${ }^{12}$. Here, we asked a question whether we can apply this coating on medical devices having complex geometries. As a proof of concept, we designed a cylindrical object that mimics the cardiovascular medical stents ${ }^{59}$ and 3D-printed it with the help of a resin-based stereolithography 3D-printer (see SI for details). The resulting transparent polymer objects (Figure 7c), which we call here as polymer medical stents, were further dip-coated (2 times) with a solution of PMMA (30 mg/mL) containing R18/F5-TPB (5 wt $\%$ ) (Figure 7c). Due to high dye concentration used, this simple coating protocol was sufficient to obtain strong surface staining, which can be seen as pink color on RGB images. These coated polymer stents showed bright fluorescence when observed under UV-light (Figure 7d). This result show that 3D printed polymeric object of a desired complex shape can be easily made fluorescent by a simple dip-coating with our dye salt/polymer blend. CONCLUSIONS 
In this work, based on a concept of ionic dye insulation with bulky hydrophobic counterions, we have developed ultrabright fluorescent polymeric materials in form of films, nanofibers and coatings. Bulky counterion acts as a spacer between the dye molecules and thus helps to overcome the fundamental problem of ACQ of dyes in polymeric matrices. With the help of a bulky hydrophobic counterion fluorinated tetraphenylborate (F5-TPB) and PMMA polymer, we transformed a series of ionic dyes into ultrabright fluorescent materials such as spin-coated thin films, electrospun nanofibers and coatings on fiducials and 3D printed medical stents.

Polymeric thin films containing dyes with small counterions were poorly emissive because of ACQ, whereas the dye films with F5-TPB systematically showed strong fluorescence and quantum yields reached as high as 130 -fold in case of R18/F5-TPB. The counterion concept worked well for both rhodamine and cyanine dyes, which enabled preparation of bright polymeric materials with varied emission color from blue to near-infrared. We also found that the bulky counterion ensures much higher stability of the fluorescent films against dye leakage in the presence of cells and serum-containing medium. Indeed, $\mathbf{R 1 8} / \mathrm{ClO}_{4}$ films exhibited significant dye leakage in these conditions, in contrast to R18/F5-TPB showing excellent stability. Moreover, these fluorescent films were not cytotoxic, allowing normal cell culture.

Fluorescent nanofibers prepared by electrospinning revealed even stronger ACQ effects for $\mathbf{R 1 8} / \mathbf{C l O}_{4}$ dye, where their emission was completely quenched at $5 \mathrm{wt} \%$ loading. On the contrary, R18/F5-TPB loaded nanofibers showed strong emission and their fluorescence intensity was $>290$-fold higher compared to $\mathbf{R 1 8} / \mathbf{C l O}_{4}$ at 5 wt \% loading. R18/F5-TPB loaded fibers displayed a strong fluorescence and high QY (31\%) even at a very high dye loading of $30 \mathrm{wt} \%$. Thus, we obtained highly emissive nanofibers at nearly 100 -fold higher loading than currently reported in literature, ${ }^{55-57}$ which implies that we improved two orders of magnitude the brightness of this type 
of materials. These studies highlight the dramatic influence of bulky counterions on the emission properties of polymeric nanofibers.

Finally, we explored our fluorescent polymeric materials as coatings. First, we showed that the formulation with the bulky counterion is essential to produce bight coating on the top of model stainless steel fiducials. Then, we have demonstrated a proof-of-concept for coating 3D-printed medical devices having complex geometries, which will open-up new possibilities for several medical applications. For example, such bright coatings on medical stents/implants or catheters can guide the surgeons to precisely place the medical devices inside the body or such coatings can be used as a fluorescent barcode on medical implants, that will help to quickly track/locate the implants inside the body as and when there is an infection or the replacement is necessary. ${ }^{60}$ Another interesting application would be to use the coating as an optical waveguide to deliver the light precisely into the deep tissues for phototherapeutic applications and this ultrabright coating material could be a handy tool in photomedicine and biosensing. We have successfully demonstrated the universality of the counterion approach by taking different ionic dyes and produced bright fluorescent materials of different colors covering the entire visible spectrum. The developed approach opens the route to a great variety of functional fluorescent polymeric materials in form of films, coating and nanofibers.

\section{ASSOCIATED CONTENT}

\section{Supporting Information.}

The supporting information is available free of charge. 
Analytical and photo physical characterization, absorption spectra of the films, absolute quantum yields, SEM and fluorescence images.

\section{AUTHOR INFORMATION}

\section{Corresponding Author}

Andrey S. Klymchenko -Laboratoire de Bioimagerie et Pathologies, UMR 7021 CNRS,

Université de Strasbourg, 74 route du Rhin, 67401, Illkirch, France.

E-mail: andrey.klymchenko@unistra.fr

\section{Author Contributions}

The manuscript was written through contributions of all authors. All authors have given approval to the final version of the manuscript.

\section{Notes}

The authors declare no competing financial interest.

\section{ACKNOWLEDGMENT}

This work and AHA are supported by SATT Conectus grants NICE and Biosensing and European Research Council ERC Consolidator grant BrightSens 648528. We acknowledge JeanLuc Weickert, IGBMC for SEM measurements.

\section{REFERENCES}

1. Zhang, H.; Zhang, B.; Zhang, Y.; Xu, Z.; Wu, H.; Yin, P.-A.; Wang, Z.; Zhao, Z.; Ma, D.; Tang, B. Z. A Multifunctional Blue-Emitting Material Designed Via Tuning Distribution of Hybridized Excited-State for High-Performance Blue and Host-Sensitized Oleds. Advanced Functional Materials 2020, 30, 2002323.

2. Hou, X.; Ke, C.; Bruns, C. J.; McGonigal, P. R.; Pettman, R. B.; Stoddart, J. F. Tunable SolidState Fluorescent Materials for Supramolecular Encryption. Nature Communications 2015, 6 , 6884. 
3. Sekine, Y.; Kim, S. B.; Zhang, Y.; Bandodkar, A. J.; Xu, S.; Choi, J.; Irie, M.; Ray, T. R.; Kohli, P.; Kozai, N.; Sugita, T.; Wu, Y.; Lee, K.; Lee, K.-T.; Ghaffari, R.; Rogers, J. A. A Fluorometric Skin-Interfaced Microfluidic Device and Smartphone Imaging Module for in Situ Quantitative Analysis of Sweat Chemistry. Lab on a Chip 2018, 18, 2178-2186.

4. Wang, J.; Dong, J. Optical Waveguides and Integrated Optical Devices for Medical Diagnosis, Health Monitoring and Light Therapies. Sensors 2020, 20, 3981.

5. A, A. H.; G, U. R.; Ali, F.; Taye, N.; Chattopadhyay, S.; Das, A. A Reagent for Specific Recognition of Cysteine in Aqueous Buffer and in Natural Milk: Imaging Studies, Enzymatic Reaction and Analysis of Whey Protein. Chemical Communications 2015, 51, 15592-15595. 6. Ashokkumar, P.; Ashoka, A. H.; Collot, M.; Das, A.; Klymchenko, A. S. A Fluorogenic Bodipy Molecular Rotor as an Apoptosis Marker. Chemical Communications 2019, 55, 69026905.

7. Ashokkumar, P.; Adarsh, N.; Klymchenko, A. S. Ratiometric Nanoparticle Probe Based on Fret-Amplified Phosphorescence for Oxygen Sensing with Minimal Phototoxicity. Small 2020, 16, 2002494.

8. Goudappagouda; Dongre, S. D.; Das, T.; Santhosh Babu, S. Dual Mode Selective Detection and Differentiation of Tnt from Other Nitroaromatic Compounds. Journal of Materials Chemistry A 2020, 8, 10767-10771.

9. Mei, J.; Leung, N. L. C.; Kwok, R. T. K.; Lam, J. W. Y.; Tang, B. Z. Aggregation-Induced Emission: Together We Shine, United We Soar! Chemical Reviews 2015, 115, 11718-11940.

10. Shimizu, M.; Hiyama, T. Organic Fluorophores Exhibiting Highly Efficient

Photoluminescence in the Solid State. Chemistry - An Asian Journal 2010, 5, 1516-1531.

11. Guan, W.; Zhou, W.; Lu, J.; Lu, C. Luminescent Films for Chemo- and Biosensing.

Chemical Society Reviews 2015, 44, 6981-7009.

12. Ashoka, A. H.; Kong, S.-H.; Seeliger, B.; Andreiuk, B.; Soares, R. V.; Barberio, M.; Diana, M.; Klymchenko, A. S. Near-Infrared Fluorescent Coatings of Medical Devices for ImageGuided Surgery. Biomaterials 2020, 261, 120306.

13. Gao, Y.; Zhang, J.; Su, Y.; Wang, H.; Wang, X.-X.; Huang, L.-P.; Yu, M.; Ramakrishna, S.; Long, Y.-Z. Recent Progress and Challenges in Solution Blow Spinning. Materials Horizons 2021.

14. Ramakrishna, S.; Fujihara, K.; Teo, W.-E.; Yong, T.; Ma, Z.; Ramaseshan, R. Electrospun Nanofibers: Solving Global Issues. Materials Today 2006, 9, 40-50.

15. Ding, B.; Wang, M.; Wang, X.; Yu, J.; Sun, G. Electrospun Nanomaterials for Ultrasensitive Sensors. Materials Today 2010, 13, 16-27.

16. Xue, J. J.; Xie, J. W.; Liu, W. Y.; Xia, Y. N. Electrospun Nanofibers: New Concepts, Materials, and Applications. Accounts Chem. Res. 2017, 50, 1976-1987.

17. Matlock-Colangelo, L.; Baeumner, A. J. Recent Progress in the Design of Nanofiber-Based Biosensing Devices. Lab on a Chip 2012, 12, 2612-2620.

18. Anzenbacher Jr, P.; Li, F.; Palacios, M. A. Toward Wearable Sensors: Fluorescent Attoreactor Mats as Optically Encoded Cross-Reactive Sensor Arrays. Angewandte Chemie International Edition 2012, 51, 2345-2348.

19. Schoolaert, E.; Hoogenboom, R.; De Clerck, K. Colorimetric Nanofibers as Optical Sensors. Advanced Functional Materials 2017, 27, 1702646.

20. Yoo, H. S.; Kim, T. G.; Park, T. G. Surface-Functionalized Electrospun Nanofibers for Tissue Engineering and Drug Delivery. Advanced Drug Delivery Reviews 2009, 61, 1033-1042. 
21. Choi, J. S.; Leong, K. W.; Yoo, H. S. In Vivo Wound Healing of Diabetic Ulcers Using Electrospun Nanofibers Immobilized with Human Epidermal Growth Factor (Egf). Biomaterials 2008, 29, 587-596.

22. Ramakrishna, S.; Mayer, J.; Wintermantel, E.; Leong, K. W. Biomedical Applications of Polymer-Composite Materials: A Review. Composites Science and Technology 2001, 61, 11891224.

23. Chen, Y.; Lam, J. W. Y.; Kwok, R. T. K.; Liu, B.; Tang, B. Z. Aggregation-Induced Emission: Fundamental Understanding and Future Developments. Materials Horizons 2019, 6, 428-433.

24. Reisch, A.; Klymchenko, A. S. Fluorescent Polymer Nanoparticles Based on Dyes: Seeking Brighter Tools for Bioimaging. Small 2016, 12, 1968-1992.

25. Wurthner, F.; Kaiser, T. E.; Saha-Moller, C. R. J-Aggregates: From Serendipitous Discovery to Supramolecular Engineering of Functional Dye Materials. Angew. Chem.-Int. Edit. 2011, 50, 3376-3410.

26. Ding, Y.; Li, W.; Wang, F.; Li, H.; Yang, S.; Wang, L.; Wang, Z.; Tebyetekerwa, M.; Tang, B. Z. Which Is a Better Fluorescent Sensor: Aggregation-Induced Emission-Based Nanofibers or Thin-Coating Films? Materials Advances 2020, 1, 574-578.

27. Hong, Y.; Lam, J. W. Y.; Tang, B. Z. Aggregation-Induced Emission: Phenomenon, Mechanism and Applications. Chemical Communications 2009, 4332-4353.

28. Wong, K.-T.; Chien, Y.-Y.; Chen, R.-T.; Wang, C.-F.; Lin, Y.-T.; Chiang, H.-H.; Hsieh, P.Y.; Wu, C.-C.; Chou, C. H.; Su, Y. O.; Lee, G.-H.; Peng, S.-M. Ter(9,9-Diarylfluorene)S: Highly Efficient Blue Emitter with Promising Electrochemical and Thermal Stability. Journal of the American Chemical Society 2002, 124, 11576-11577.

29. Anthony, S. P. Organic Solid-State Fluorescence: Strategies for Generating Switchable and Tunable Fluorescent Materials. ChemPlusChem 2012, 77, 518-531.

30. Anthony, J. E.; Brooks, J. S.; Eaton, D. L.; Parkin, S. R. Functionalized Pentacene: Improved Electronic Properties from Control of Solid-State Order. Journal of the American Chemical Society 2001, 123, 9482-9483.

31. Zhang, B.; Soleimaninejad, H.; Jones, D. J.; White, J. M.; Ghiggino, K. P.; Smith, T. A.; Wong, W. W. H. Highly Fluorescent Molecularly Insulated Perylene Diimides: Effect of Concentration on Photophysical Properties. Chemistry of Materials 2017, 29, 8395-8403. 32. Schmidt, D.; Stolte, M.; Süß, J.; Liess, A.; Stepanenko, V.; Würthner, F. Protein-Like Enwrapped Perylene Bisimide Chromophore as a Bright Microcrystalline Emitter Material. Angewandte Chemie International Edition 2019, 58, 13385-13389.

33. Duan, C.; Zhou, Y.; Shan, G.-G.; Chen, Y.; Zhao, W.; Yuan, D.; Zeng, L.; Huang, X.; Niu, G. Bright Solid-State Red-Emissive Bodipys: Facile Synthesis and Their High-Contrast Mechanochromic Properties. Journal of Materials Chemistry C 2019, 7, 3471-3478. 34. Tsai, W.-K.; Wang, C.-I.; Liao, C.-H.; Yao, C.-N.; Kuo, T.-J.; Liu, M.-H.; Hsu, C.-P.; Lin, S.-Y.; Wu, C.-Y.; Pyle, J. R.; Chen, J.; Chan, Y.-H. Molecular Design of near-Infrared Fluorescent Pdots for Tumor Targeting: Aggregation-Induced Emission Versus AntiAggregation-Caused Quenching. Chemical Science 2019, 10, 198-207.

35. Ding, W.; Sun, J.; Chen, G.; Zhou, L.; Wang, J.; Gu, X.; Wan, J.; Pu, X.; Tang, B.; Wang, Z. L. Stretchable Multi-Luminescent Fibers with Aiegens. Journal of Materials Chemistry C 2019, 7, 10769-10776. 
36. Zhai, C.; Schreiber, C. L.; Padilla-Coley, S.; Oliver, A. G.; Smith, B. D. Fluorescent SelfThreaded Peptide Probes for Biological Imaging. Angewandte Chemie International Edition 2020, 59, 23740-23747.

37. Luo, J.; Xie, Z.; Lam, J. W. Y.; Cheng, L.; Chen, H.; Qiu, C.; Kwok, H. S.; Zhan, X.; Liu, Y.; Zhu, D.; Tang, B. Z. Aggregation-Induced Emission of 1-Methyl-1,2,3,4,5-

Pentaphenylsilole. Chemical Communications 2001, 1740-1741.

38. Zhao, W.; Liu, Z.; Yu, J.; Lu, X.; Lam, J. W. Y.; Sun, J.; He, Z.; Ma, H.; Tang, B. Z. Turning on Solid-State Luminescence by Phototriggered Subtle Molecular Conformation Variations. Advanced Materials 2020, 33, 2006844.

39. Li, W.; Ding, Y.; Tebyetekerwa, M.; Xie, Y.; Wang, L.; Li, H.; Hu, R.; Wang, Z.; Qin, A.;

Tang, B. Z. Fluorescent Aggregation-Induced Emission (Aie)-Based Thermosetting Electrospun Nanofibers: Fabrication, Properties and Applications. Materials Chemistry Frontiers 2019, 3, 2491-2498.

40. Ling, X.; Huang, L.; Li, Y.; Wan, Q.; Wang, Z.; Qin, A.; Gao, M.; Tang, B. Z.

Photoactivatable Dihydroalkaloids for Cancer Cell Imaging and Chemotherapy with High Spatiotemporal Resolution. Materials Horizons 2020, 7, 2696-2701.

41. Geng, J.; Li, K.; Qin, W.; Ma, L.; Gurzadyan, G. G.; Tang, B. Z.; Liu, B. Eccentric Loading of Fluorogen with Aggregation-Induced Emission in Plga Matrix Increases Nanoparticle Fluorescence Quantum Yield for Targeted Cellular Imaging. Small 2013, 9, 2012-2019.

42. Reisch, A.; Didier, P.; Richert, L.; Oncul, S.; Arntz, Y.; Mély, Y.; Klymchenko, A. S. Collective Fluorescence Switching of Counterion-Assembled Dyes in Polymer Nanoparticles. Nature Communications 2014, 5, 4089.

43. Trofymchuk, K.; Reisch, A.; Didier, P.; Fras, F.; Gilliot, P.; Mely, Y.; Klymchenko, A. S. Giant Light-Harvesting Nanoantenna for Single-Molecule Detection in Ambient Light. Nature Photonics 2017, 11, 657-663.

44. Trofymchuk, K.; Valanciunaite, J.; Andreiuk, B.; Reisch, A.; Collot, M.; Klymchenko, A. S. Bodipy-Loaded Polymer Nanoparticles: Chemical Structure of Cargo Defines Leakage from Nanocarrier in Living Cells. J Mater Chem B 2019, 7, 5199-5210.

45. Aparin, I. O.; Melnychuk, N.; Klymchenko, A. S. Ionic Aggregation-Induced Emission: Bulky Hydrophobic Counterions Light up Dyes in Polymeric Nanoparticles. Adv. Optical Mater. 2020, 8, 2000027.

46. Andreiuk, B.; Reisch, A.; Bernhardt, E.; Klymchenko, A. S. Fighting Aggregation-Caused

Quenching and Leakage of Dyes in Fluorescent Polymer Nanoparticles: Universal Role of Counterion. Chemistry - An Asian Journal 2019, 14, 836-846.

47. Reisch, A.; Trofymchuk, K.; Runser, A.; Fleith, G.; Rawiso, M.; Klymchenko, A. S. Tailoring Fluorescence Brightness and Switching of Nanoparticles through Dye Organization in the Polymer Matrix. ACS Applied Materials \& Interfaces 2017, 9, 43030-43042.

48. Melnychuk, N.; Klymchenko, A. S. DNA-Functionalized Dye-Loaded Polymeric Nanoparticles: Ultrabright Fret Platform for Amplified Detection of Nucleic Acids. Journal of the American Chemical Society 2018, 140, 10856-10865.

49. Melnychuk, N.; Egloff, S.; Runser, A.; Reisch, A.; Klymchenko, A. S. Light-Harvesting Nanoparticle Probes for Fret-Based Detection of Oligonucleotides with Single-Molecule Sensitivity. Angewandte Chemie International Edition 2020, 59, 6811-6818.

50. Barberio, M.; Pizzicannella, M.; Spota, A.; Ashoka, A. H.; Agnus, V.; Al Taher, M.; JansenWinkeln, B.; Gockel, I.; Marescaux, J.; Swanström, L.; Kong, S.-H.; Felli, E.; Klymchenko, A.; Diana, M. Preoperative Endoscopic Marking of the Gastrointestinal Tract Using Fluorescence 
Imaging: Submucosal Indocyanine Green Tattooing Versus a Novel Fluorescent over-the-Scope Clip in a Survival Experimental Study. Surgical Endoscopy 2020, https://doi.org/10.1007/s00464-020-07999-2.

51. Benson, C. R.; Kacenauskaite, L.; VanDenburgh, K. L.; Zhao, W.; Qiao, B.; Sadhukhan, T.; Pink, M.; Chen, J.; Borgi, S.; Chen, C.-H.; Davis, B. J.; Simon, Y. C.; Raghavachari, K.; Laursen, B. W.; Flood, A. H. Plug-and-Play Optical Materials from Fluorescent Dyes and Macrocycles. Chem 2020, 6, 1978-1997.

52. Collot, M.; Ashokkumar, P.; Anton, H.; Boutant, E.; Faklaris, O.; Galli, T.; Mely, Y.; Danglot, L.; Klymchenko, A. S. Membright: A Family of Fluorescent Membrane Probes for Advanced Cellular Imaging and Neuroscience. Cell Chemical Biology 2019, 26, 600-614.e607. 53. Andreiuk, B.; Reisch, A.; Lindecker, M.; Follain, G.; Peyrieras, N.; Goetz, J. G.; Klymchenko, A. S. Fluorescent Polymer Nanoparticles for Cell Barcoding in Vitro and in Vivo. Small 2017, 13, 1701582.

54. Shulov, I.; Oncul, S.; Reisch, A.; Arntz, Y.; Collot, M.; Mely, Y.; Klymchenko, A. S. Fluorinated Counterion-Enhanced Emission of Rhodamine Aggregates: Ultrabright Nanoparticles for Bioimaging and Light-Harvesting. Nanoscale 2015, 7, 18198-18210. 55. Krammer, S.; Vannahme, C.; Smith, C. L. C.; Grossmann, T.; Jenne, M.; Schierle, S.; Jorgensen, L.; Chronakis, I. S.; Kristensen, A.; Kalt, H. Random-Cavity Lasing from Electrospun Polymer Fiber Networks. Advanced Materials 2014, 26, 8096-8100.

56. Huang, D. F.; Li, T. S.; Liu, S. Y.; Yi, T.; Wang, C. K.; Li, J.; Liu, X. Y.; Xu, M. Random Lasing Action from Electrospun Nanofibers Doped with Laser Dyes. Laser Phys. 2017, $27,7$. 57. Wang, H. G.; Yang, Q. B.; Sun, L.; Wang, S. A.; Wang, W.; Zhang, C. Q.; Li, Y. C.; Xu, S. F.; Li, Y. X. Aggregation States of Rhodamine 6g in Electrospun Nanofibrous Films. J. Colloid Interface Sci. 2010, 341, 224-231.

58. Pang, L.; Ming, J.; Pan, F.; Ning, X. Fabrication of Silk Fibroin Fluorescent Nanofibers Via Electrospinning. Polymers 2019, 11, 986.

59. McMahon, S.; Bertollo, N.; Cearbhaill, E. D. O.; Salber, J.; Pierucci, L.; Duffy, P.; Dürig, T.; Bi, V.; Wang, W. Bio-Resorbable Polymer Stents: A Review of Material Progress and Prospects. Progress in Polymer Science 2018, 83, 79-96.

60. Vertes, A.; Hitchins, V.; Phillips, K. S. Analytical Challenges of Microbial Biofilms on Medical Devices. Analytical Chemistry 2012, 84, 3858-3866. 
Table of Contents

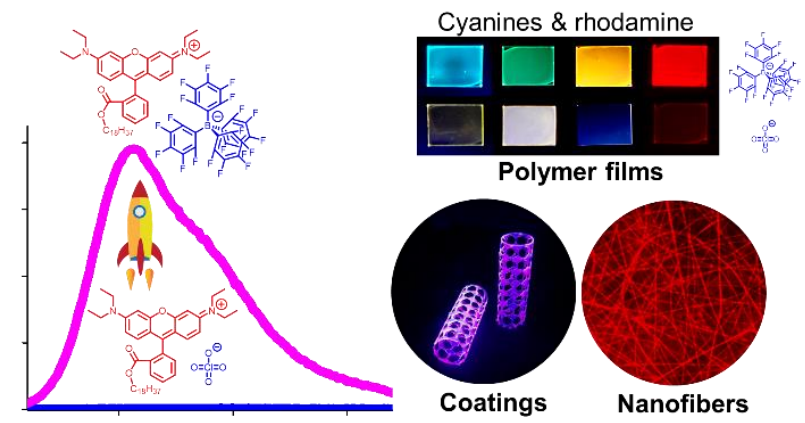

